\title{
The ABCs of Math Attitudes: Reliability and Validity of the Three Factor Model
}

\author{
Soung Hwa Walker \\ Graduate School of Education at University of California, Riverside \\ E-mail: sounghwa.walker@ucr.edu \\ Deron Walker \\ Dept. of Modern Languages \& Literature at California Baptist University \\ E-mail: dwalker@calbaptist.edu \\ Keith F. Widaman \\ Graduate Division at University of California, Riverside \\ E-mail: keith.widaman@ucr.edu
}

Received: Nov. 3, 2019 Accepted: Dec. 11, $2019 \quad$ Published: February 1, 2020

doi:10.5296/jse.v10i1.15792ＵRL: https://doi.org/10.5296/jse.v10i1.15792

\begin{abstract}
Although the Attitudes toward Mathematics Inventory (ATMI; four-factor model with 40 items) has been well-established as a viable tool to test the multidimensionality of math attitudes, studies have pointed out that the ATMI is lengthy, and analyses have typically been conducted on individual samples from either western or non-western cultural contexts. To address these concerns, the present study aimed to evaluate a shorter version of math attitude scales (three-factor model with 11 items) using data from three nationally representative samples (USA, Hong Kong, and Singapore). The primary goal of the current investigation was to establish reliability and validity of the factor structure of Affective-Behavioral-Cognitive math attitudes. Alpha coefficients (.74 - .91), factor loadings (.49 - .90), and inter-item correlation matrices supported strong reliability and clear convergent and discriminant validity of all three subscales of math attitudes. Findings were consistent with the well-documented theoretical model of ABC math attitudes (Eagly \& Chaiken, 1998, 2007; Walker, 2018; Zan \& Di Martino, 2007, 2014) as well as the classical tripartite model of attitudes from social psychology (Breckler, 1984; Rosenberg \& Hovland, 1960). Implications of the ABC model of math attitudes on math education, limitations of the present study, and future research are discussed.
\end{abstract}

Keywords: Math Attitudes, Affective-Behavioral-Cognitive, Reliability, Validity 


\section{Introduction}

Significant research evidence demonstrates that attitudes toward math reflect more than what has been indicated with simple one-dimensional evaluations of the subject matter that vary from negative to positive (Aiken, 1974; Hannula, 2002; Lim \& Chapman, 2013; Majeed, Darmawan, \& Lynch, 2013; McLeod, 1992; Neale, 1969; Tapia, 1996; Tapia \& Marsh, 2002, 2004; Zan \& Di Martino, 2007, 2014). That is, attitudes toward math can be best understood from a multidimensional point of view that contains several distinctive components. To increase participation and intellectual engagement in math classrooms, "the National Council of Teachers of Mathematics (1989) and the National Research Council (1989) have encouraged mathematics educators to incorporate affective factors with cognitive factors in mathematics teaching and learning" (Ma \& Kishor, 1997, p. 26). Moreover, in terms of the positive impact of attitudes on math learning, Suydam and Weaver (1975) argued that students learn more effectively and achieve higher when they are interested in and like what they learn.

In other words, when students hold favorable attitudes toward math-related tasks, they are more likely to engage in those targeted tasks and tend to put more effort into completing their work with high quality, which contributes to positive behavioral outcomes (e.g., performing better on math tests and/or earning higher grades in math courses). Consequently, numerous studies have examined the effects of various components of math attitudes (e.g., enjoyment/liking, motivation, self-confidence, and perceived value) on math achievement (e.g., Khine, Al-Mutawah, \& Afari, 2015; Simegn \& Asfaw, 2018) to provide a more comprehensive picture of math learning processes. However, subscales of math attitudes should be validated as reliable measurements for assessing math attitudes. Therefore, the aim of the present study was to examine the validity and reliability of the affective-behavioral-cognitive factors of math attitudes (that contains 11 items), with three national groups (USA, Singapore, and Hong Kong). What follows represents a brief historical background of math attitudes research in terms of theoretical and measurement development.

\section{Theoretical Development of Multidimensional Math Attitudes}

Derived from the field of social psychology, the early definition of attitudes referred to "a mental and neural state of readiness, organized through experience," that influences people's action/response to particular objects or situations (Allport, 1935, p. 810). Generally speaking, attitudes are conceptualized as learned predispositions or tendencies to respond to certain objects, situations, or tasks either favorably or unfavorably (Aiken, 1970; Fishbein, 1967). Neale (1969) posited four sub-categories in math attitudes: (1) dis/liking math, (2) a tendency to be involved in or to avoid math activity, (3) a belief that s/he is good or bad at math, and (4) usefulness or uselessness of math. In addition, Hannula (2002), in his analytical framework based on a case study, identified four aspects of math attitudes: (1) emotions aroused in the situation, (2) emotions associated with the stimuli, (3) expected consequences, and (4) relating the situation to personal values.

Meanwhile, a slightly different conceptualization of evaluative processes of math attitudes has also been examined. In this research tradition, three separate evaluative processes 
(affective, behavioral, and cognitive math attitudes) are hypothesized to represent how students respond to math work / math related situations / math as a subject matter (Eagly \& Chaiken, 1998; Zan \& Di Martino, 2014). From a theoretical perspective, the Affective-Behavioral-Cognitive model of attitudes toward math (i.e., ABC model of math attitudes) appears to be very similar to the classical tripartite model of attitude from social psychology (Bagozzi, Tybout, Craig, \& Sternthal, 1979; Breckler, 1984; Rosenberg \& Hovland, 1960). According to the tripartite model of attitudes framework, the affective component of attitudes could be measured by collecting participants' reports of their feelings or moods about the target task, object, or situation. The behavioral component of attitudes could be measured by participants' responses regarding their behavioral intentions, actions, and such. The cognitive component of attitudes could be measured by collecting participants' responses about their beliefs or thoughts about specific tasks or subject matter.

In a similar vein, the $\mathrm{ABC}$ model of math attitudes includes three distinctive factors: namely, affective, behavioral, and cognitive factors. The affective component of math attitudes describes emotional reactions to math such as 'students dis/like reading about math,' and 'students are doing math because they like or enjoy it,' etc. The behavioral component describes academic behavioral tendencies related to math. Such examples could include 'students work hard on preparing math exams,' and 'students are studying math until they understand the materials,' etc. The cognitive component of math attitudes describes one's belief about his/her capabilities in learning math. For example, 'students believe that it is up to them to do well on math,' and 'students believe that they can succeed in math if they put enough efforts,' etc. Although many comprehensive theoretical models of attitudes toward math have been developed (Eagly \& Chaiken, 1998, 2007; Hannula, 2002; Neale, 1969; Zan \& Di Martino, 2007, 2014), limited empirical research has been conducted to investigate the replication of the factorial structure of the $\mathrm{ABC}$ model of attitudes toward math across multiple population samples.

\section{Multidimensional Scales of Math Attitudes}

Numerous measurement research studies have demonstrated the validity of the multidimensional structure of math attitudes. For example, the Fennema-Sherman Mathematics Attitudes Scales (FSMAS; Fennema \& Sherman, 1976) has been widely used to measure attitudes toward math (Chamberlin, 2010, Lim \& Chapman, 2013; Majeed et al., 2013; Pepin, 2011). Aiken's Mathematics Attitudes Scales (MAS; Aiken, 1974) has also been well recognized in math education research (Majeed et a., 2013; Watson, 1983). In his study, Aiken (1974) examined the revised version of MAS (11 items for Enjoyment and 10 items for Value) using freshman students from a southeastern college (i.e., 100 women and 90 men), and reported that Enjoyment and Value were separate factors of math attitudes. The correlations of Enjoyment and Value with SAT-Math were $r=.38$ and .27, respectively (Aiken, 1974). In 2004, Tapia and Marsh examined the reliability and validity of the Attitudes Toward Math Inventory (ATMI) with 134 undergraduate students enrolled in math classes at a state university in the United States with the 40 items of ATMI: 10 Enjoyment, 5 Motivation, 15 Self-Confidence, and 10 Value. The results of a Confirmatory Factor Analysis (CFA) supported the initial four-factor structure of Tapia's (1996) ATMI. The reported reliability for 
each sub-scale of the ATMI ranged from .87 to .96 (Tapia \& March, 2004). Although ATMI, consisting of 40-items, has been well recognized in the literature, research has indicated ATMI is rather lengthy and used limited population samples.

To confirm whether the four-factor model of ATMI would be a reliable and valid instrument to measure math attitudes in a different cultural setting, Majeed et al. (2013) conducted a study in a Southern Australian context. They examined the applicability of the 40 items of ATMI with middle school students $(\mathrm{n}=699)$ from 17 different schools in Southern Australia. The authors only used 32 items (i.e., 9 Enjoyment, 12 Self-Confidence, 7 Value, and 4 Motivation) for their analyses as they found some redundancy among items from the 1996 Tapia ATMI. Results of the CFA (32 items of ATMI) confirmed that the hypothesized four-factor structure of ATMI was verified. Furthermore, Lim and Chapman (2013) reasoned that earlier instruments measuring math attitudes have been considered outdated and rather lengthy. Thus, they created the shorter version of the ATMI (i.e., 5 Enjoyment, 4 Motivation, 5 Self-Confidence, and 5 Perceived-Value). To test the validity of the modified and shortened 19 items of ATMI, data were collected from 1,601 math major students enrolled in pre-tertiary institutions in Singapore. The results of a CFA indicated that the shorter version of ATMI yielded a four-factor model as a good representation for measuring math attitudes; all factor loadings were significant $(\mathrm{ENJ}=.65-.86 ; \mathrm{MOT}=.71-.80 ; \mathrm{SC}=.79-.83$; VAL $=.67-81)$. Additionally, internal consistencies of the four components of math attitudes from both sub-samples $(\mathrm{n}=800$ and 801$)$ and test-retest reliability $(n=208)$ were high; Cronbach alpha $(\alpha)=.84-.90$ and test-retest reliability $\left(r_{\mathrm{xx}}\right)=.75$, respectively. Even though the updated version of ATMI with 19 items provided reasonable results, Lim and Chapman (2013) reported that "future administration should exclude the MOT [motivation component of math attitudes] subscale" that might produce better internal consistency values, which suggests that only 15 of the 40 ATMI items should be used for practical purposes (i.e., 5 enjoyment, 5 self-confidence, and 5 value items of ATMI).

More recently, the $5^{\text {th }}$ Trends of International Mathematics and Science Studies (TIMSS) in 2011 also provided three subscales of math attitudes: (1) intrinsic value - liking math, (2) utility value - valuing math, and (3) beliefs in ability - confidence in math (Mullis, Martin, Foy, \& Arora, 2012). Utilizing a 20-item self-reported questionnaire of math attitudes from the 2011 TIMSS, Khine et al. (2015) conceptualized that the three sub-domain attitudinal factors (i.e., Liking, Value, and Confidence) would each predict math achievement. By surveying 387 high school students in the United Arab Emirates, Khine et al. (2015) found that only Confidence turned out to be a significant predictor of math achievement $(\beta=.62, p$ $<.001)$, while Liking and Value factors were not significant $(\beta \mathrm{s}=.13$ and -.16, $p \mathrm{~s}>.10$, respectively).

\section{Aims of the Present Study}

The primary goal of the present study was to assess the psychometric properties of the ABC three-factor model of math attitudes that comprises 11 items from the 2012 PISA Student Background Questionnaires (SBQs). The following two main concerns guided the present study. The first concern was that a unidimensional approach would provide a limited view on 
math attitudes because one's attitudes toward math should involve more than a simplistic evaluation of whether a student dis/likes or has a positive/negative evaluation of mathematics. The second concern was that the four-factor model of the ATMI is too long for many studies (e.g., 40 items or a shortened 32 items) and has been evaluated in a limited set of population samples. Therefore, the present study aimed to establish that the ABC three-factor model would be a better fit to the data than a single-model of math attitudes across three large, nationally representative samples. In doing so, factor structures would be compared (single-factor vs. three-factor model). Then, the reliability and validity of the three-factor model would be assessed by examining factor loadings, internal consistency reliabilities, and correlation matrices for all three countries. Specifically, the focus of the present study was to provide empirical evidence for the structure of the affective-behavioral-cognitive theoretical model that has been presented by Zan and Di Martino $(2007,2014)$ and Eagly and Chaiken (1998, 2007). Figure 1 shows a visual representation of both the single-factor and the three-factor (ABC) models. For the single-factor model, all 11 observed variables are allowed to load onto one factor - which represents a general attitude factor. In contrast, for the three-factor model, variables from \#1 to \#4 load onto the affective factor, variables from $\# 5$ to \#8 load onto the behavioral factor, and variable \#9 to \#11 load onto the cognitive factor.
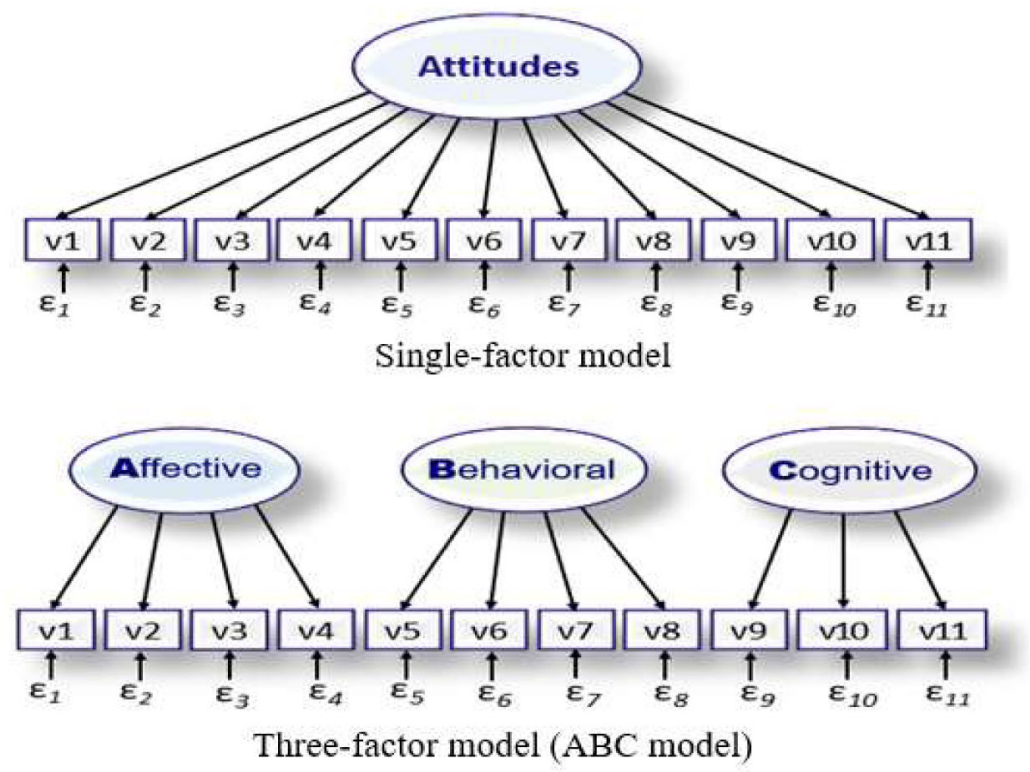

Figure 1. Structural representation of three-factor model vs. one factor model of math attitudes

\section{Methods}

\subsection{Data Source and Measures}

Sample data from students from the USA $(\mathrm{N}=3142)$, Singapore $(\mathrm{N}=3663)$, and Hong Kong $(\mathrm{N}=3046)$ from the 2012 PISA were used in this present investigation for the following reasons. First, the reported 2012 PISA math scores of Singapore $(M=573)$ and Hong Kong $(M=561)$ were among the top-five high-achieving countries, whereas the math score of the USA $(M=381)$ was below average among the 65 OECD participating countries $(M=494)$. 
Although Asian students performed significantly better than Western students, Leung (2002) reported that Asian students have more negative attitudes toward math. Second, in 2011 TIMSS, $4^{\text {th }}$ and $8^{\text {th }}$ graders in Singapore ( $M \mathrm{~s}=606$ and 611 , respectively) and in Hong Kong (Ms $=602$ and 609, respectively) again performed significantly better in math than the rest of their counterparts around the world (overall TIMSS $M=500$ in 2011), while math scores of both $4^{\text {th }}$ and $8^{\text {th }}$ graders in the USA ( $M \mathrm{~s}=541$ and 509 , respectively) were again much lower than those of Asian countries.

Thus, it is of interest to investigate whether the three-factor ABC model of math attitudes would fit well in each of the three national samples to investigate how different aspects of math attitudes are associated with math achievement in various cultural contexts. The variables (11 survey items) used for the present study from the Student Background Questionnaires (SBQs) of 2012 PISA were reported on a 4-point Likert-type scale; i.e., $1=$ strongly agree, $2=$ agree, $3=$ disagree, and $4=$ strongly disagree (OECD, 2014). However, for convenience, all measured items were reverse scored. That is, 4 became strongly agree to 1 strongly disagree, so that higher numbers would represent more positive attitudes, which would be easier to interpret. Table 1 presents descriptive statistics (mean score of each observed variable with standard deviation).

Table 1. Descriptive statistics for all variables used in the analyses

\begin{tabular}{|c|c|c|c|c|c|c|c|}
\hline \multirow[b]{2}{*}{ Items } & \multirow[b]{2}{*}{ Descriptions } & \multicolumn{2}{|c|}{$\begin{array}{c}\text { USA } \\
(\mathrm{N}=3142)\end{array}$} & \multicolumn{2}{|c|}{$\begin{array}{l}\text { Singapore } \\
(\mathrm{N}=\mathbf{3 6 6 3})\end{array}$} & \multicolumn{2}{|c|}{$\begin{array}{c}\text { Hong Kong } \\
(\mathrm{N}=\mathbf{3 0 4 6})\end{array}$} \\
\hline & & Mean & SD & Mean & SD & Mean & $\overline{\text { SD }}$ \\
\hline $\mathbf{V 1}$ & I enjoy reading about math & 2.19 & .83 & 2.79 & .83 & 2.41 & .82 \\
\hline $\mathbf{V 2}$ & I look forward to my math lessons & 2.43 & .89 & 2.98 & .80 & 2.50 & .84 \\
\hline $\mathbf{V 3}$ & I do math because I enjoy it & 2.27 & .93 & 2.95 & .87 & 2.60 & .89 \\
\hline V4 & $\begin{array}{l}\text { I am Interested in the things I learn in } \\
\text { math }\end{array}$ & 2.52 & .89 & 3.00 & .80 & 2.55 & .85 \\
\hline V5 & I finish my math homework in time & 3.12 & .76 & 2.98 & .77 & 2.94 & .76 \\
\hline V6 & I work hard on my math homework & 3.00 & .74 & 3.07 & .71 & 2.90 & .72 \\
\hline $\mathbf{V 7}$ & I study hard for math quizzes & 2.59 & .82 & 2.83 & .76 & 2.54 & .75 \\
\hline $\mathbf{V 8}$ & $\begin{array}{l}\text { I keep studying until I understand math } \\
\text { material }\end{array}$ & 2.70 & .81 & 2.97 & .75 & 2.70 & .78 \\
\hline V9 & $\begin{array}{l}\text { If putting enough effort, I can succeed in } \\
\text { math }\end{array}$ & 3.46 & .68 & 3.62 & .54 & 3.27 & .67 \\
\hline $\mathbf{V 1 0}$ & I do well in math is completely up to me & 3.21 & .74 & 3.41 & .71 & 3.10 & .75 \\
\hline V11 & If I wanted to, I could do well in math & 3.27 & .72 & 3.47 & .64 & 3.23 & .69 \\
\hline
\end{tabular}

Note. Sample size listed for each country represents the number of students who completed survey questions related to math attitudes

\subsection{Statistical Analyses}

Initial data screening was done through SAS 9.4 (obtaining three national sample datasets from 65 OECD participating countries in 2012 PISA), and structural equation modeling 
(SEM) techniques through Mplus 7 (Muthén \& Muthén, 1998-2012) was employed for the main data analyses. SEM allows researchers to be explicit about their theory, and to specify, estimate, and test the hypothesized interrelations among manifest variables based on latent variables (Crowley \& Fan, 1997; Kline, 2011; Nachtigall, Kroehne, Funke, \& Steyer, 2003; Raykov \& Marcoulides, 2006; Ullman, 2006; Widaman \& Thompson, 2003). For the present study, Multigroup Confirmatory Factor Analysis (MGCFA; Joreskog, 1971) was conducted to test whether a three-factor model fit better than a one-factor model using data from three countries (i.e., USA, Singapore, and Hong Kong samples). The principle of multigroup analysis in CFA as opposed to a single-group analysis is to fit factor models in several groups simultaneously (Joreskog, 1971; Lubke, Dolan, Kelderman, \& Mellenbergh, 2003). The relations between multiple observed variables and multiple common factors in a matrix format can be specified as follows:

$$
\mathrm{X}=\tau+\Lambda \mathrm{x} \xi+\delta
$$

where $\mathrm{X}$ is a vector of observed variables, $\tau$ is a vector of intercepts, $\Lambda \mathrm{x}$ is matrix of factor loadings, $\xi$ is a vector of common factors, and $\delta$ is a vector of unique variables. When evaluating model fit, Chi-Square $\left(\chi^{2}\right)$ testing, Root-Mean-Square Error of Approximation (RMSEA; Browne \& Cudeck, 1993) with confidence interval, standardized-root-mean square residual (SRMR), Tucker-Lewis Index (TLI; Tucker \& Lewis, 1973), and Comparative Fit Index (CFI; Bentler,1990) were reported. It is suggested that a good fitting model should have values of CFI and TLI $\geq .90$, RMSEA and SRMR $\leq .08$ (Browne \& Cudeck, 1993; Byrne, 1989; Hu \& Bentler 1999; Kline, 2011; Raykov \& Marcoulides, 2006).

\section{Results}

With the SEM framework, MGCFA was conducted to (1) evaluate whether the measurement of observed variables would be equivalent across all countries and (2) test a better fitting model between a single-factor and three-factor models of math attitudes. Among other techniques, MGCFA (Joreskog, 1971) has been the most widely used method to assess measurement invariance across distinctive group memberships such as cultural, gender, age/grade level, or national groups (Cheung \& Rensvold, 2002; Meredith, 1993; Steinmetz, Schmidt, Tina-Booh, Wieczorek, \& Schwartz, 2009; Widaman \& Riese, 1997; Windle, Iwawaki, \& Lerner, 1988). Then, separate CFAs were conducted for each country to further illustrate statistical significance of model differences between single-factor (i.e., one-factor) and three-factor models of math attitudes. Table 2 presents results of the model fit comparison with several fit indices. The single-factor model included all 11 items (observed variables) as indicators of a unidimensional construct, whereas the three-factor model included 3 factors ( 4 items for affective, 4 items for behavioral, and 3 items for cognitive factors of math attitudes) as a multidimensional construct (see also Figure 1). As the various models subjected to CFA were nested designs, the change of chi-square statistics (Hu \& Bentler, 1995) was used to test for model fit differences along with several other fit indices.

As shown in Table 2, the three-factor model resulted in an excellent fit to the data as the values of $\chi^{2}$ were reduced greatly from single-factor to three-factor models; $\Delta \chi^{2}(9)=$ $10533.828, p<.001$ across three national groups, $\Delta \chi^{2}(3)=3792.226, p<.001$ for USA, $\Delta \chi^{2}(3)$ $=3530.07, p<.001$ for Singapore, and $\Delta \chi^{2}(3)=3211.53, p<.001$ for Hong Kong, 
respectively. Additionally, it is important to note that RMSEAs ranged from .040 to .058 and SRMRs were all less than $.05(.027-.041)$, which satisfied the recommended values of less than .08 from the measurement literatures. Furthermore, CFIs and TLIs were greater than .95 (i.e., .976 - .988), which met the suggested criteria from the measurement invariance literatures (Browne \& Cudeck, 1993; Byrne, 1996; Hu \& Bentler 1999; Kline, 2011; Raykov $\&$ Marcoulides, 2006). To summarize, the results of MGCFA and CFAs support the factorial structure of the ABC model of math attitudes for all three national samples.

Table 2. Model comparison between one-factor and three-factor models

\begin{tabular}{|c|c|c|c|c|c|c|}
\hline MODEL & $\chi^{2}$ & df & RMSEA $(90 \%$ CI $)$ & CFI & TLI & SRMR \\
\hline \multicolumn{7}{|c|}{ USA, Singapore, and Hong Kong } \\
\hline One-factor & 11542.476 & 129 & $.164(.162-.167)$ & .783 & .722 & .108 \\
\hline Three-factor & 1008.648 & 120 & $.047(.045-.050)$ & .983 & .977 & .032 \\
\hline \multicolumn{7}{|l|}{$\overline{\text { USA }}$} \\
\hline One-factor & 4249.706 & 43 & $.176(.172-.181)$ & .754 & .685 & .120 \\
\hline Three-factor & 457.477 & 40 & $.058(.053-.062)$ & .976 & .966 & .041 \\
\hline \multicolumn{7}{|l|}{ Singapore } \\
\hline One-factor & 3799.204 & 43 & $.154(.150-.159)$ & .797 & .740 & .104 \\
\hline Three-factor & 269.136 & 40 & $.040(.035-.044)$ & .988 & .983 & .026 \\
\hline \multicolumn{7}{|l|}{ Hong Kong } \\
\hline One-factor & 3493.566 & 43 & $.162(.158-.167)$ & 0.796 & .739 & .101 \\
\hline Three-factor & 282.035 & 40 & $.045(.040-.051)$ & 0.986 & .980 & .027 \\
\hline
\end{tabular}

Note. RMSEA = Root Mean Square Error of Approximation; CI = Confidence Interval; CFI = Comparative Fit Index; TLI $=$ Tucker Lewis Index, SRMR $=$ Standardized Root Mean Square Residuals.

In Table 3, the bolded values in highlighted are to show strong inter-correlations within factors, which indicates the evidence of convergent validity. Discriminant (or divergent) validity, on the hand, aims to examine unrelatedness among latent factors. In other words, correlations with $\mathrm{A} 1$ and $\mathrm{B} 1, r=.19, \mathrm{~A} 1$ and $\mathrm{C} 1 ; r=.28$ when compared to $\mathrm{A} 1$ and $\mathrm{A} 2 ; r$ $=.65$ for the USA. That is, correlations with variables among affective factor are higher (i.e., $.65<r<.78$ ) than variables between affective and behavioral factors (i.e., . $19<r<.39$ ) for the USA, which is the top correlation matrix. For Singapore, correlations with variables among affective factor are also higher (i.e., .62<r<.76) than variables between affective and behavioral factors (i.e., . $28<\mathrm{r}<.41$ ), which is the middle correlation matrix. For Hong Kong, correlations with variables among affective factor are also higher (i.e., .65 $<r<.76$ ) than variables between affective and behavioral factors (i.e., $.24<\mathrm{r}<.47$ ), which is the bottom correlation matrix. Although not perfect, the correlation matrices clearly displayed overall convergent and discriminant validity of all three factors of math attitudes for national sample data from the USA, Singapore, and Hong Kong. 


\section{MInstitute Machin $_{\text {Int }}$}

Table 3. Inter-item correlation matrix for three countries (USA, Singapore, \& Hong Kong)

\begin{tabular}{|c|c|c|c|c|c|c|c|c|c|c|c|}
\hline & A1 & A2 & A3 & A4 & B1 & B2 & B3 & B4 & C1 & $\mathrm{C} 2$ & C3 \\
\hline \multicolumn{12}{|c|}{ Affective } \\
\hline A1 & -- & & & & & & & & & & \\
\hline A2 & .65 & -- & & & & & & & & & \\
\hline $\mathbf{A 3}$ & .70 & .78 & -- & & & & & & & & \\
\hline A4 & .66 & .76 & .76 & -- & & & & & & & \\
\hline \multicolumn{12}{|c|}{ Behavior } \\
\hline B1 & .19 & .25 & .25 & .26 & -- & & & & & & \\
\hline B2 & .24 & .35 & .32 & .34 & .63 & -- & & & & & \\
\hline B3 & .24 & .30 & .27 & .29 & .38 & .53 & -- & & & & \\
\hline B4 & .32 & .37 & .36 & .39 & .39 & .50 & .67 & -- & & & \\
\hline \multicolumn{12}{|c|}{ Cognitive } \\
\hline C1 & .27 & .35 & .33 & .38 & .33 & .31 & .21 & .30 & -- & & \\
\hline $\mathrm{C} 2$ & .21 & .26 & .26 & .29 & .21 & .19 & .16 & .22 & .49 & -- & \\
\hline $\mathrm{C} 3$ & .24 & .28 & .28 & .32 & .24 & .19 & .10 & .21 & .53 & .48 & -- \\
\hline \multicolumn{12}{|c|}{ Affective } \\
\hline A1 & -- & & & & & & & & & & \\
\hline A2 & .62 & -- & & & & & & & & & \\
\hline $\mathbf{A 3}$ & .72 & .70 & -- & & & & & & & & \\
\hline A4 & .68 & .66 & .76 & -- & & & & & & & \\
\hline \multicolumn{12}{|c|}{ Behavior } \\
\hline B1 & .29 & .34 & .32 & .29 & -- & & & & & & \\
\hline B2 & .35 & .43 & .41 & .38 & .64 & -- & & & & & \\
\hline B3 & .36 & .38 & .38 & .35 & .47 & .56 & -- & & & & \\
\hline B4 & .39 & .40 & .43 & .41 & .42 & .50 & .55 & -- & & & \\
\hline \multicolumn{12}{|c|}{ Cognitive } \\
\hline C1 & .28 & .30 & .33 & .31 & .17 & .25 & .17 & .28 & -- & & \\
\hline $\mathrm{C} 2$ & .17 & .17 & .21 & .20 & .13 & .16 & .09 & .17 & .48 & -- & \\
\hline $\mathrm{C3}$ & .23 & .21 & .27 & .25 & .12 & .16 & .12 & .22 & .53 & .47 & -- \\
\hline
\end{tabular}

\section{Affective}

A1

A2

A3

.65

A3

67

A4

$\begin{array}{lll}.73 & .72 & .76\end{array}$

Behavior

$\begin{array}{lllllrrr}\text { B1 } & .24 & .29 & .28 & .27 & -- & & \\ \text { B2 } & .37 & .43 & .43 & .41 & \mathbf{. 6 3} & -- & \\ \text { B3 } & .27 & .32 & .31 & .31 & \mathbf{. 3 8} & \mathbf{. 5 0} & -- \\ \text { B4 } & .43 & .43 & .47 & .47 & \mathbf{. 3 7} & \mathbf{. 5 1} & \mathbf{. 5 2}\end{array}$

Cognitive

\begin{tabular}{llllllllllll}
$\mathbf{C 1}$ & .38 & .37 & .39 & .38 & .22 & .28 & .19 & .33 & -- & & \\
$\mathbf{C 2}$ & .30 & .30 & .33 & .31 & .14 & .19 & .11 & .24 & $\mathbf{. 5 8}$ & -- & \\
$\mathbf{C 3}$ & .35 & .31 & .35 & .35 & .14 & .23 & .14 & .27 & $\mathbf{. 6 4}$ & $\mathbf{. 5 6}$ & -- \\
\hline
\end{tabular}

Note. All correlations are significant at the 0.01 level (2-tailed). 


\section{MInstitute Macrothink $^{\text {Int }}$}

Table 4 presents item correlations with each total factor score and estimated factor loadings. As indicated, item correlations with total factor score were strong in all three countries; .74< $r<.92$ for the USA, .77<r<.91 for Singapore, and .76<r<91 for Hong Kong, respectively. In addition, all estimated factor loadings were relatively high (ranged from .74 - .92 for the USA, from .68 to .90 for Singapore, and from .51 to .88 for Hong Kong), and all standard errors were close to zero. Based on the literature on reliability and validity measurement, a factor loading of less than .30 or .40 would consider weak validity of items (e.g., Abu-Hilal, Abdelfattah, Alshumrani, Abduljabbar, \& Marsh, 2013; Majeed et al., 2013).

Table 4. Item correlation with total factor score and measurement model parameter estimates

\begin{tabular}{|c|c|c|c|c|c|c|c|c|c|}
\hline \multirow[b]{2}{*}{ Factor and its items } & \multicolumn{3}{|c|}{ USA } & \multicolumn{3}{|c|}{ Singapore } & \multicolumn{3}{|c|}{ Hong Kong } \\
\hline & $\mathbf{r}$ & $\lambda$ & S.E. & $\mathbf{r}$ & $\lambda$ & S.E. & $\mathbf{r}$ & $\lambda$ & S.E. \\
\hline \multicolumn{10}{|l|}{ Affective factor } \\
\hline $\mathbf{A 1}$ & .84 & .76 & .008 & .86 & .80 & .007 & .86 & .80 & .007 \\
\hline $\mathbf{A 2}$ & .90 & .87 & .006 & .85 & .79 & .007 & .88 & .83 & .007 \\
\hline $\mathbf{A 3}$ & .92 & .89 & .005 & .91 & .90 & .005 & .90 & .86 & .006 \\
\hline A4 & .90 & .86 & .006 & .88 & .85 & .006 & .91 & .89 & .005 \\
\hline \multicolumn{10}{|l|}{ Behavioral factor } \\
\hline B1 & .74 & .49 & .016 & .79 & .60 & .013 & .76 & .51 & .017 \\
\hline B2 & .82 & .65 & .013 & .84 & .73 & .011 & .84 & .71 & .013 \\
\hline B3 & .82 & .79 & .010 & .81 & .75 & .010 & .77 & .66 & .013 \\
\hline B4 & .81 & .83 & .010 & .77 & .72 & .011 & .77 & .77 & .012 \\
\hline \multicolumn{10}{|l|}{ Cognitive factor } \\
\hline C1 & .80 & .72 & .013 & .79 & .77 & .012 & .86 & .83 & .010 \\
\hline $\mathrm{C} 2$ & .82 & .66 & .014 & .83 & .64 & .013 & .85 & .71 & .012 \\
\hline C3 & .83 & .69 & .013 & .82 & .70 & .013 & .85 & .77 & .011 \\
\hline
\end{tabular}

Note. $\mathrm{r}=$ item correlation with total factor score; $\lambda=$ estimated standardized factor loading; S.E. $=$ standard error

Table 5 reports latent variable (factor) mean, Alpha coefficients, and averaged item inter-correlations. The values of Alpha coefficients and mean correlations are to show internal consistency of items (reliability). Alpha coefficients are considered the inter-relatedness of the total set of the observed items for each latent variable, and have been widely used to examine the reliability of measured items. Reliability refers to consistency and stability of measurement (Drost, 2011; Rosenthal \& Rosnow, 1991). The value of .70 and higher of alpha coefficients suggests good evidence of reliability (Cronbach, 1951). As shown in Table 5, all alpha coefficients are ranged from .74 to .91, which confirms the strong reliability of all items across three different national contexts. 
Table 5. Latent variable (factor) mean, Cronbach's Alpha, and averaged item correlation

\begin{tabular}{|c|c|c|c|c|c|c|c|c|c|}
\hline & \multicolumn{3}{|c|}{ USA } & \multicolumn{3}{|c|}{ Singapore } & \multicolumn{3}{|c|}{ Hong Kong } \\
\hline & $\begin{array}{c}\mathrm{LV} \\
\text { mean }\end{array}$ & $\alpha$ & $\begin{array}{c}\mathrm{r} \\
\text { mean }\end{array}$ & $\begin{array}{c}\mathrm{LV} \\
\text { mean }\end{array}$ & $\alpha$ & $\begin{array}{c}\mathrm{r} \\
\text { mean }\end{array}$ & $\begin{array}{c}\mathrm{LV} \\
\text { mean }\end{array}$ & $\alpha$ & $\begin{array}{c}\mathrm{r} \\
\text { mean }\end{array}$ \\
\hline Affective & 2.35 & .91 & .72 & 2.93 & .90 & .69 & 2.51 & .91 & .71 \\
\hline Behavioral & 2.85 & .81 & .52 & 2.96 & .81 & .52 & 2.77 & .79 & .49 \\
\hline Cognitive & 3.32 & .75 & .50 & 3.50 & .75 & .50 & 3.20 & .82 & .59 \\
\hline
\end{tabular}

Note. $\mathrm{LV}$ mean $=$ Latent variable or factor mean; $\alpha=$ standardized Alpha coefficient; $\mathrm{r}$ mean $=$ averaged inter-item correlation. Scales were from 1 as strongly disagree to 4 as strongly agree.

Table 6 presents correlations among all factors and with math achievement. As shown in Table 6 , the correlations of three subcomponents of math attitudes are strong $(.25<r<.53)$ in all three countries. However, the correlation between the behavioral component of math attitudes and math achievement in the USA $(r=.06)$ seems to be significantly lower than in Singapore $(r=.12)$ and Hong Kong $(r=.21)$. The correlation between the affective factor and math achievement in Singapore $(r=.07)$ seems to be significantly lower than in the USA $(r=.14)$ and in Hong Kong $(r=.31)$. Meanwhile, the correlations between all three factors of math attitudes and math achievement seem to be strong in Hong Kong $(.19<r<.31)$.

Table 6 correlations among subcomponent factors of math attitudes and math achievement

\begin{tabular}{|c|c|c|c|c|c|c|c|c|c|c|c|c|}
\hline & \multicolumn{4}{|c|}{ USA } & \multicolumn{4}{|c|}{ Singapore } & \multicolumn{4}{|c|}{ Hong Kong } \\
\hline & 1 & 2 & 3 & 4 & 1 & 2 & 3 & 4 & 1 & 2 & 3 & 4 \\
\hline 1. Affective & -- & & & & -- & & & & -- & & & \\
\hline 2. Behavioral & .42 & -- & & & .53 & -- & & & .52 & -- & & \\
\hline 3. Cognitive & .40 & .33 & -- & & .33 & .25 & -- & & .45 & .31 & -- & \\
\hline 4. Math & .14 & .06 & .24 & -- & .07 & .12 & .11 & -- & .31 & .21 & .19 & -- \\
\hline
\end{tabular}

Note. math $=$ average of the 5 plausible values of math achievement score; 484.97 for the USA $(n=3142)$, 567.96 for Singapore $(n=3663)$, and 562.15 for Hong Kong $(n=3046)$. All correlations are statistically significant, $p \mathrm{~s}<.01$ (two-tailed).

\section{Discussion}

The primary goal of the present study was to assess the psychometric properties of the three-factor model of math attitudes from three different national contexts using the 2012 PISA data. Three different population samples were used to reduce the likelihood that the results occurred by chance. Results of MGCFA and CFAs confirmed that the three-factor model (4 items of affective, 4 items of behavioral, and 3 items of cognitve subscales) was an excellent fit to the data across all three countries. In addition, factor loadings $(.49-.90)$ and Alpha coefficients $(.74-.91)$ indicated strong convergent validity and reliability of all three subscales of math attitudes. Furthermore, inter-item correlation matrices supported clear convergent and discriminant validity. More importantly, the findings further establish the validity and reliability of the theorized model of "Affective-Behavioral-Cognitive math attitudes" by Zan and Di Martino (2007, 2014), Eagly and Chaiken (1998; 2007), Walker 
(2018), and the classical tripartite model of attitudes from social pyschology (Breckler, 1984; Rosenberg \& Hovland, 1960).

Among others, one notable finding from Table 5 was that the Cognitive mean scores were higher than the other two factors of math attitudes from all three countries: 3.32 for the USA, 3.50 for Singapore, and 3.20 for Hong Kong, respectively. While the results have been consistent for the USA, previous studies have suggested that Asian students lack confidence in their cognitive ability despite their high academic achievement when compared to their counterparts around the world (e.g., Leung, 2002; Liu \& Meng, 2010). The present study's results may suggest a generational shift in culture among Asian adolescents. It could be interpreted that students in Asia are becoming more expressive due to influences from youth culture and globalization. Thus, traditional generalizations about Asian students' academic modesty should be treated with slight skepticism as conceptualizations of culture grow increasingly sophisticated.

As Atkinson (2004) noted, cultural representations need to be more dynamic than traditional monolithic representations of ethnic culture often portray since a person's generational, school, and professional cultures also play a role in influencing an individual's identity. However, cautionary intepretation of cultural differences is advised based on the limited investigation on math attitudes of 15 years old students from Hong Kong, Singapore, and in the USA. More importantly, deeper and more sophisticated analysis of cultural differences regarding math attitudes between Asian and Western countries' adolescents are beyond the scope of the present study. Follow-up studies might investigate cultural differences in more detail.

\section{Implications and Future Research}

Considering that the unidimensional model may present only a limited view of math attitudes, this study further established the validity, reliability and efficiency of the multidemensional ABCs of math attitudes. This is important because the three-factor model may potentially provide a more insightful and sophisticated picture of math attitudes related to math achievement as opposed to a single-factor (unidimensional) model. Additionally, considering that the four-factor ATMI model includes lengthy survey questionnaires (i.e., 40 items), the present study suggests an alternative (and perhaps, more doable for K-12 students) survey instrument of math attitudes that was utilized from the 2012 PISA SBQs. Certainly, the theoretically grounded ABCs of three-factor model of math attitudes (Eagly \& Chaiken, 1998, 2007; Walker, 2018; Zan \& Di Martino, 2007, 2014) does not suggest that the well-established and reputable four-factor model of ATMI should be discredited. The goal of the present study was to establish reliability and validity of the $\mathrm{ABCs}$ of math attitudes from the 2012 PISA SBQs with multiple national samples.

Besides ATMI questionnaires, researchers should consider using the three-factor ABC model as another viable tool to measure math atttiudes across age, gender, and ethnic groups. It is much shorter (11 items total) than ATMI four-factor model (40 items total). For math educators, it may empower them to more efficiently motivate math students to improve all areas of attitudes because each component of math attitudes plays a significant role 
influencing how students feel about math, how they behave toward math work, and how they think of learning math as well as math related future jobs. In fact, Zan, Brown, Evans, and Hannula (2006) have asserted that it is vital to have proper understanding of the interrelations among sub-domains of attitudes as they are closely related to achievement in math.

\section{References}

Abu-Hilal, M. M., Abdelfattah, F. A., Alshumrani, S. A., Abduljabbar, A. S., \& Marsh, H. W. (2013). Construct validity of self-concept in TIMSS's student background questionnaire: A test of separation and conflation of cognitive and affective dimensions of self-concept among Saudi eighth graders. European Journal of Psychology of Education, 28(4), 1201-1220. https://doi.org/10.1007/s10212-012-0162-1

Aiken, L. R. (1970). Attitudes toward mathematics. Review of Educational Research, 40(4), 551-596. https://doi.org/10.3102/00346543040004551

Aiken, L. R. (1974). Two scales of attitude toward mathematics. Journal for Research in Mathematics Education, 5(2), 67-71. https://doi.org/10.2307/748616

Allport, G. W. (1935). Attitudes. In C. Murchison (Ed.), Handbook of social psychology (pp. 798 - 844), Worcester, MA: Clark University Press.

Atkinson, D. (2004). Contrasting rhetorics/contrasting cultures: Why contrastive rhetoric needs a better conceptualization of culture. Journal of English for Academic Purposes, 3(4), 277-289. https://doi.org/10.1016/j.jeap.2004.07.002

Bagozzi, R. P., Tybout, A. M., Craig, C. S., \& Sternthal, B. (1979). The construct validity of the tripartite classification of attitudes. Journal of Marketing Research, 16(1), 88-95. https://doi.org/10.1177/002224377901600113

Bentler, P. M. (1990). Comparative fit indexes in structural models. Psychological Bulletin, 107, 238-246. https://doi.org/10.1037/0033-295X.86.5.452

Breckler, S. J. (1984). Empirical validation of affect, behavior, and cognition as distinct components of attitude. Journal of Personality and Social Psychology, 47(6), 1191-1205. https://doi.org/10.1037/0022-3514.47.6.1191

Browne, M. W., \& Cudeck, R. (1993). Alternative ways of assessing model fit. In K. A. Bollen \& J. S. Long (Eds.). Testing structural equation models (pp. 136-162). Newbury Park, CA: Sage.

Byrne, B. M. (1989). A primer of LISREL: Basic applications and programming for confirmatory factor analytic models. New York: Springer. https://doi.org/10.1007/978-1-4613-8885-2

Chamberlin, S. A. (2010). A review of instruments created to assess affect in mathematics. Journal of Mathematics Education, 3(1), 167-182.

Cheung, G. W., \& Rensvold, R. B. (2002). Evaluating goodness-of-fit indexes for testing measurement invariance. Structural Equation Modeling, 9(2), 233-255. 
https://doi.org/10.1207/S15328007SEM0902_5

Cronbach, L. J. (1951). Coefficient alpha and the internal structure of tests. Psychometrika, 16(3), 297-334. https://doi.org/10.1007/BF02310555.

Crowley, S. L., \& Fan, X. (1997). Structural equation modeling: Basic concepts and applications in personality assessment research. Journal of Personality Assessment, 68(3), 508-531. https://doi.org/10.1207/s15327752jpa6803_4

Drost, E. A. (2011). Validity and reliability in social science research. Education Research and Perspectives, 38(1), 105-123.

Eagly, A. H., \& Chaiken, S. (1998). Attitude structure and function. In D. T. Gilbert, S. T. Fiske, \& G. Lindzey (Eds.), The handbook of social psychology (pp. 269-322). New York: McGraw-Hill.

Eagly, A. H., \& Chaiken, S. (2007). The advantages of an inclusive definition of attitude. Social Cognition, 25(5), 582-602. https://doi.org/10.1521/soco.2007.25.5.582

Fennema, E., \& Sherman, J. A. (1976). Fennema-Sherman mathematics attitudes scales: Instruments designed to measure attitudes toward the learning of mathematics by males and females. Journal for Research in Mathematics Education, 7(5), 324-326. https://doi.org/10.2307/748467

Fishbein, M. (1967). Attitude and the prediction of behavior. In M. Fishbein (Ed.), Attitude theory and measurement (pp. 477-492). New York: Wiley.

Hannula, M. S. (2002). Attitude towards mathematics: Emotions, expectations and values. Educational Studies in Mathematics, 49(1), 25-46. https://doi.org/10.1023/A:1016048823497

Hu, L. T., \& Bentler, P. M. (1999). Cutoff criteria for fit indexes in covariance structure analysis: Conventional criteria versus new alternatives. Structural Equation Modeling: A Multidisciplinary Journal, 6(1), 1-55. https://doi.org/10.1080/10705519909540118

Joreskog, K. G. (1971). Simultaneous factor analysis in several populations. Psychometrika, 36, 409-426. https://doi.org/10.1007/BF02291366

Khine, M. S., Al-Mutawah, M., \& Afari, E. (2015). Determinants of affective factors in mathematics achievement: Structural equation modeling approach. Journal of Studies in Education, 5(2), 199-211. http://dx.doi.org/10.5296/jse.v5i2.7484

Kline, R. B. (2011). Principles and practice of structural equation modeling ( $3^{\text {rd }}$ Ed.). New York, NY: Guilford.

Lim, S. Y., \& Chapman, E. (2013). Development of a short form of the attitudes toward mathematics inventory. Educational Studies in Mathematics, 82(1), 145-164. http://dx.doi.org/10.1007/s10649-012-9414-x

Leung, F. K. (2002). Behind the high achievement of East Asian students. Educational Research and Evaluation, 8(1), 87-108. https://doi.org/10.1076/edre.8.1.87.6920 


\section{Macrothink}

Journal of Studies in Education

ISSN 2162-6952

2020, Vol. 10, No. 1

Liu, S., \& Meng, L. (2010). Re-examining factor structure of the attitudinal items from TIMSS 2003 in cross-cultural study of mathematics self-concept, Educational Psychology, 30(6), 699-712. https://doi.org/10.1080/01443410.2010.501102

Lubke, G. H., Dolan, C. V., Kelderman, H., \& Mellenbergh, G. J. (2003). On the relationship between sources of within-and between-group differences and measurement invariance in the $\begin{array}{llll}\text { common factor } \quad \text { model. } & \text { Intelligence, }\end{array}$ https://doi.org/10.1016/S0160-2896(03)00051-5

Ma, X. \& Kishor, N. (1997). Assessing the relationship between attitude toward mathematics and achievement in mathematics: A meta-analysis. Journal for Research in Mathematics Education, 28(1), 26-47. http://dx.doi.org/10.2307/749662

Majeed, A.A., Darmawan, G.N., \& Lynch, P. (2013). A confirmatory factor analysis of the Attitudes Toward Mathematics Inventory (ATMI). The Mathematics Educator, 15, 121-135.

McLeod, D. (1992). Research on affect in mathematics education: A reconceptualization. In D. Grows (Ed.), Handbook of Research on Mathematics Teaching and Learning (pp.575-596). New York: McMillan Publishing Company.

Meredith, W. (1993). Measurement invariance, factor analysis and factorial invariance. Psychometrika, 58(4), 525-43. https://doi.org/10.1007/BF02294825

Mullis, I.V.S., Martin, M.O., Foy, P. \& Arora, A. (2012). TIMSS 2011 International results in mathematics. Boston: TIMSS and PIRLS International Study Centre.

Muthén, L.K. and Muthén, B.O. (1998-2012). Mplus user's guide (6 ${ }^{\text {th }}$ Ed.). Los Angeles, CA: Muthén \& Muthén.

Nachtigall, C., Kroehne, U., Funke, F., \& Steyer, R. (2003). (Why) should we use SEM? Pros and cons of structural equation modeling. Methods of Psychological Research Online, 8(2), $1-22$.

National Council of Teachers of Mathematics. (1989). Curriculum and evaluation standards for school mathematics. Reston, VA: Author.

National Research Council. (1989). Everybody counts: A report to the nation on the future of mathematics education. Washington, DC: National Academy.

Neale, D. (1969). The role of attitudes in learning mathematics. The Arithmetic Teacher, 16(8), 631-641.

OECD (2014). PISA 2012 Results: Creative problem solving: students' skills in tackling real-life problems. PISA, Paris: http://dx.doi.org/10.1787/9789264208070-en

Pepin, B. (2011). Pupils' attitudes towards mathematics: A comparative study of Norwegian and English secondary students. ZDM: The International Journal on Mathematics Education, 43, 535-546. https://doi.org/10.1007/s11858-011-0314-9 
Raykov, T., \& Marcoulides, G. (2006). A first course in structural equation modeling ( $2^{\text {nd }}$ Ed.). Mahwah, NJ: Lawrence Erlbaum.

Rosenberg, M. J., \& Hovland, C. I. (1960). Cognitive, affective, and behavioral components of attitude. In M. J. Rosenberg, C. I. Hovland, W. J. McGuire, R. P. Abelson, \& J. W. Brehm (Eds.), Attitude organization and change: An analysis of consistency among attitude components (pp. 1 - 14). New Haven, CT: Yale University Press.

Rosenthal, R., \& Rosnow, R. L. (1991). Essentials of behavioral research: Methods and data analysis $\left(2^{\text {nd }}\right.$ ed.). NY: McGraw-Hill Publishing Company.

Simegn, E. M., \& Asfaw, Z. G. (2018). Assessing the influence of attitude towards mathematics on achievement of grade 10 and 12 female students in comparison with their male counterparts: Wolkite, Ethiopia. International Journal of Secondary Education, 5(5), 56-68. https://doi.org/10.11648/j.ijsedu.20170505.11

Steinmetz, H., Schmidt, P., Tina-Booh, A., Wieczorek, S., \& Schwartz, S. H. (2009). Testing measurement invariance using multigroup CFA: Differences between educational groups in human values measurement. Quality \& Quantity, 43(4), 599-616. https://doi.org/10.1007/s11135-007-9143-x

Suydam, M. N., \& Weaver, J. F. (1975). Research on mathematics learning. In J. N. Payne (Ed.), Mathematics learning in early childhood: Thirty-seventh yearbook (pp. 44-67). Reston, VA: National Council of Teachers of Mathematics.

Tapia, M. (1996). The attitudes toward mathematics instrument. Paper presented at the annual meeting of the Mid-south Educational Research Association, Tuscaloosa, AL (ERIC Reproduction Service No. ED 404165).

Tapia, M., \& II Marsh, G. E. (2002). Confirmatory factor analysis of the attitudes toward mathematics inventory. Paper presented at the annual meeting of the Mid-South Educational Research Association, Chattanooga, Tennessee.

Tapia, M., \& II Marsh, G. E. (2004). An instrument to measure mathematics attitudes. Academic Exchange Quarterly, 8(2), 16-21.

Tucker, L. R., \& Lewis, C. (1973). A reliability coefficient for maximum likelihood factor analysis. Psychometrika, 38, 1-10. https://doi.org/10.1007/BF02291170

Ullman, J. B. (2006). Structural equation modeling: Reviewing the basics and moving forward. Journal of Personality Assessment, $87(1), \quad 35-50$. https://doi.org/10.1207/s15327752jpa8701_03

Walker, S. H. (2018). Reliability, validity, and measurement invariance of attitudinal and social norm factors in math. Journal of Studies in Education, 8(3), 37-51. https://doi.org/10.5296/jse.v8i3.13340. 


\section{NI Macrothink}

Journal of Studies in Education

ISSN 2162-6952 2020, Vol. 10, No. 1

Watson, J. M. (1983). The Aiken attitude to mathematics scales: Psychometric data on reliability and discriminant validity. Educational and Psychological Measurement, 43(4), 1247-1253. https://doi.org/10.1177/001316448304300436

Widaman. F., \& Reise, S. P. (1997). Exploring the measurement invariance of psychological instruments: Applications in the substance use domain. In K. J. Bryant, M. Windle, \& S. G. West (Eds.), The science of prevention: Methodological advances from alcohol and substance abuse research (pp. 281-324). Washington, DC: American Psychological Association. https://doi.org/10.1037/10222-009

Widaman, K. F., \& Thompson, J. S. (2003). On specifying the null model for incremental fit indices in structural equation modeling. Psychological Methods, 8, 16-37. https://doi.org/10.1037/1082-989X.8.1.16

Windle, M., Iwawaki, S., \& Lerner, R. M. (1988). Cross-cultural comparability of temperament among Japanese and American preschool children. International Journal of Psychology, 23, 547-567. https://doi.org/10.1080/00207598808247785

Zan, R., \& Di Martino, P. (2007). Attitude toward mathematics: Overcoming the positive/negative dichotomy. The Montana Mathematics Enthusiast, 3, 157-168.

Zan, R., \& Di Martino, P. (2014). Students' attitude in mathematics education. In Encyclopedia of mathematics education (pp. 572-577). Dordrecht, Netherlands: Springer. https://doi.org/10.1007/978-94-007-4978-8_146

Zan, R., Brown, L., Evans, J., \& Hannula, M. S. (2006). Affect in mathematics education: An introduction. Educational Studies in Mathematics, 63(2), 113-121. https://doi.org/10.1007/s10649-006-9028-2

\section{Copyright Disclaimer}

Copyright for this article is retained by the author(s), with first publication rights granted to the journal.

This is an open-access article distributed under the terms and conditions of the Creative Commons Attribution license (http://creativecommons.org/licenses/by/3.0/). 